\title{
MECHANICAL APPROACH AS ERROR PROOFING TO PREVENT WRONG ORIENTATION OF PRODUCT
}

\author{
Arif Rahman Hakim \\ Mechanical Department of Engineering Faculty of UNRIKA
}

\section{Introduction}

Error or mistake is occurred in such away that causing product malfunction, machine not working, process produce defective. All of these affect the quality and productivity, further more will increase cost of production.

Many aspects can create error, such as human, design, process, raw material, method and environment. A lot of effort put in place to prevent or eliminate error. Detection by inspection is old method applied in industry. Detection can be applied pre production or post production. Both of method has their own advantages. Inspection prior production will ensure the input are free from defect, while inspection post production is to prevent defect escape to customer.

In many industries nowdays, inspection still being carried out by human. This type of inspection has been affected by human capability which is very hard to be consistent at all time. In Integrated Circuit Assembly manufacturing, some problem may happen due to wrong orientation and or misalignment of production part. This research is carried out in one of IC assembly manufacture in Batam.

\section{The Dimensions of Quality}

The word "Quality" is a common word that we are frequently hear in daily live. Everybody familiar even keeps saying this word. Perhaps, if we ask their opinion on what the "quality" means, many of them cannot explain clearly. Actually, the "quality" has a lot of dimensions that we can refer to. One of common perception about quality is the fulfillment of product criteria or specification. Some people correlate the quality with the satisfaction. In other word, a product (goods or service) is considered has good quality if it can satisfy its user.

Several dimensions of quality that can be used as reference; 
Performance: the primary operating characteristics of a product such as acceleration of an automobile, clarity of a TV picture.

Features: "Bell and Whistles", such as extra cycle on a washer or free breakfast at a hotel.

Reliability: Probability of continuing to function as intended over a product's normal lifetime.

Conformance: the degree to which a product's characteristics meet pre-established standards, such as the diameter of a part.

Durability: A measure of the expected lifetime of the product. This lifetime may depend upon the type of use.

Serviceability: Ease of getting a product repaired as well as the speed, courtesy, and competence of personnel who must repair the product.

Aesthetics: Personal reactions to a product's appearance, feel, taste, etc.

Reputation: The perception consumers have about a product based on the company's reputation, previous experience with other product from that company, or comments made by others.

\section{Understanding Of Quality}

When a product is at design stage, designer has defined several characteristics or specifications must be fulfilled by the product. These characteristic or specifications are derived from technical requirement, voice of customer and applicable regulations. Quality is compliant to the requirement defined to the products. During production stage, products experiencing several steps of processes, that may incur problems which create non compliant to the product requirements. This non compliant called as defect. Statistical method can be applied at the process to control the defect rates.

Defect rate when tolerance is defined in terms of number of standard deviations of the process, process capability index $(\mathrm{CpK})$ or defective part per million $(\mathrm{dppm})$ given that the process is operating in statistical control. 
Table 1. Correlations of statistical control indexes

\begin{tabular}{|c|c|c|c|}
\hline $\begin{array}{c}\text { No. of } \\
\text { Standard } \\
\text { Deviations }\end{array}$ & $\begin{array}{c}\text { Process } \\
\text { Capability } \\
\text { Index }\end{array}$ & $\begin{array}{c}\text { Defect } \\
\text { Rate (\%) }\end{array}$ & $\begin{array}{c}\text { Part per } \\
\text { Million }\end{array}$ \\
\hline$+/-1.0$ & 0.333 & 31.74 & 317.4 \\
\hline$+/-2.0$ & 0.667 & 4.56 & 45.6 \\
\hline$+/-3.0$ & 1 & 0.27 & 2.7 \\
\hline$+/-4.0$ & 1.333 & 0.0063 & 63 \\
\hline$+/-5.0$ & 1.667 & 0.000057 & 0.57 \\
\hline$+/-6.0$ & 2 & 0.0000002 & 0.002 \\
\hline
\end{tabular}

\section{Cost of quality}

A known person in quality management named Philip Crosby has stated that "Quality is free. It's not a gift, but it's free. What costs money are the un-quality things - all the actions that involve not doing jobs right the first time". What does it mean? If we do our job right at the first time, then we will get our job done compliance to the requirement without any additional resources. In reverse, if we did wrongly, then what we will get is the result that non compliance with the requirement. There are some possibilities will happen to the product such as re-do, repair or scrap the product. It means we waste money, time, effort and other resources. This additional resources becoming additional cost to get the product meet its quality requirement. If we did right at the first time, no additional cost incur to get the quality. This what we means with "the quality is free".

In fact, nothing perfect in our lives. Including in the process of production. Anything may go wrong or running not as what the expectation. Therefore, we need to apply control plan to ensure everything run as what we plan, in case anything goes wrong, control will alert us to make correction. Control can be applied at the input of the process or in the process itself or controlling the output of the process. We need to ensure the control is effective to prevent the error or at least to detect the error so then the defect does not go to the customer. Application of 
control in the production line needs cost named as internal cost. Even more, the consequences of the defect escapee to the customer will cost us also, called as external cost. Internal cost for the control such as; defect prevention, appraisal (defect detection), internal failure, while external cost includes warranty claim, product recall, customer dissatisfaction, legal action and lost of customers.

\section{Zero defect}

Now days, more customer requires stringent requirement. They no longer can tolerate any defect on the product that they bought. Referring to table 1, if a production process is in a statistical control at $+/-3 \square$, it means the process potentially produce 27 defective in one million units product. If the processed improved to $+/-6 \square \square \square$ it still has potentially produce 2 defective in one billion units product. Its really a small number compared with the total production. However, in the perception of customer, this very small number can be intolerable matter. To give a clear picture, a producer produce one billion mobile phone with the process control +/- $6 \mathrm{~s}$. During production, 2 defective were produced and not detected by the control in place. These 2 defective go to the market and bought by the customer. It is clear that when the customer got the defective one, it means he got 100\% defect product. The sales can not tell the customer that 2 defectives is out of one billion products and it should be tolerable. Customer still receive 100\% defective. Therefore, more producer is requested to apply new concept that named as Zero Defect.

\section{Elements of Production}

We can classify the elements of production activity into 5 (five) elements. They are material, machine, method, man and information. Those five elements synergized in production activity. However, each of element may create problem that produce defective. Material as input of process probably has contained the problem that causing defect product. For example, material used in production was poor quality. Machine can contribute to produce defect product if it malfunctions. While man who running the process can make error in operating the machine or do wrong set up of the machine. In several cases, man make mistakes due to in-discipline attitude to follow procedure. Method can be cause of problem when it was not defined clearly or 
it contains the wrong step in the procedures. Un clear information also can be a cause of problem in the production.

\section{Five Elements of Production}

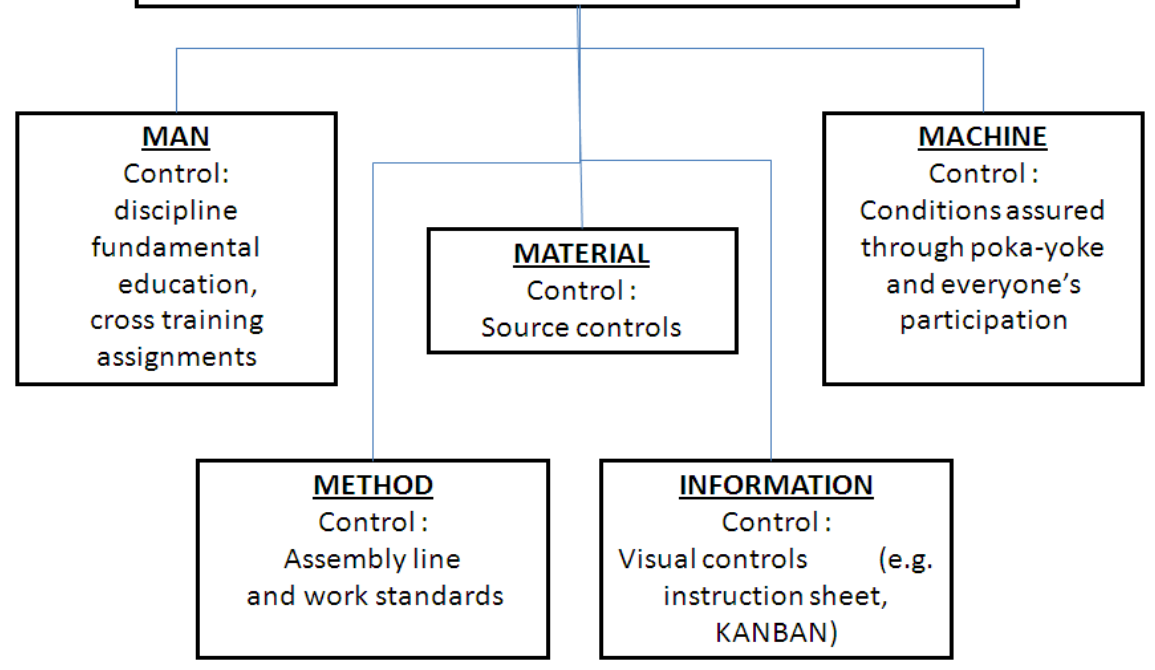

Fig.1 Element of production

\section{What Causes Defects?}

Variation exist in any process, it is in evitable. Variation may cause defect to happen. Year to year people want to reduce the variation in the effort to get the high consistence quality of product. By reducing the variation, the process becoming more capable and robust. Process capability index $(\mathrm{CpK})$ is a non dimensional unit used to measure the capability of process. The higher $\mathrm{CpK}$ indicate high capability of process. Referring to table $1, \mathrm{CpK}$ value 2 is similar to $0.002 \mathrm{dpm}$. CpK is related to variation of process that is represented by standard deviation ( $\square$ ) and the specification of product.

$$
\mathrm{CpK}=\frac{(\mathrm{USL}-\text { Xaverage} \text { Xaverage }-\mathrm{LSL})_{\text {minimum }}}{\mathrm{n} \sigma}
$$

Where;

$\mathrm{CpK}=$ Process capability index

USL = Upper Specification Limit

LSL = Lower Specification Limit

Xaverage $=$ average value of characteristic 
$\sigma \quad=$ standard deviation of process

$\mathrm{n} \quad=$ number of standard deviation used in calculation

Source of variation of a process can be classified into common cause (85\%) and assignable cause $(15 \%)$.

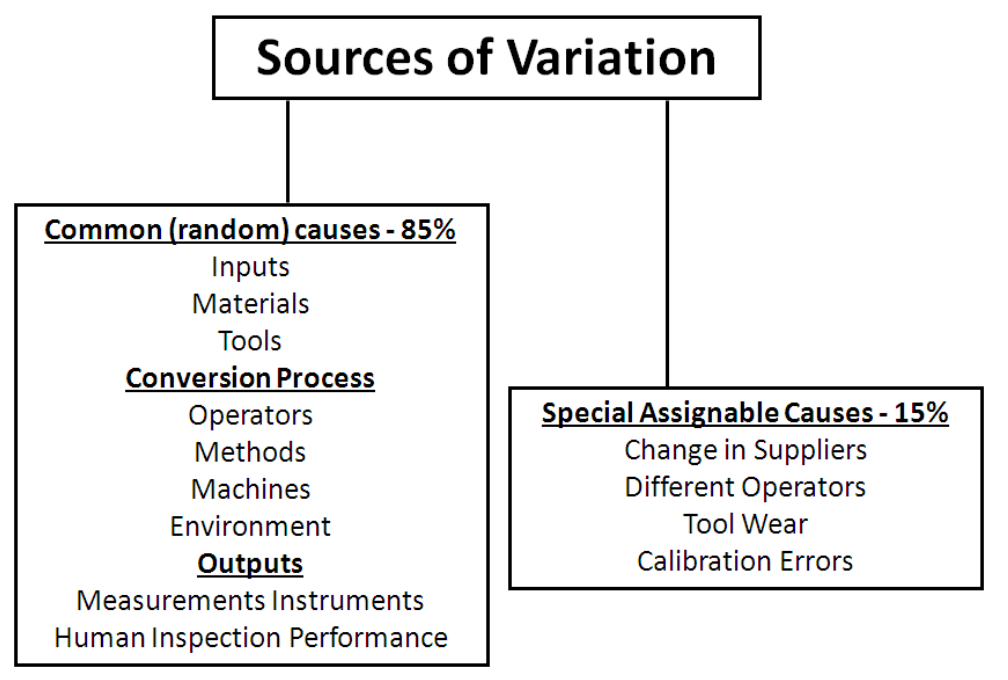

Fig.2 Source of variation

Aside of process variation, defects may be caused by;

1. Inappropriate procedures or standards are specified when the process is planned. For example if the wrong heat treatment temperature is specified all products will be defective.

2. Damaged or excessively variable materials might be used. Material as an input of process contributes to the quality of product.

3. Worn machines part (for example, bearing or tools) can lead to defect.

4. Finally even when the first four situations are just right; simple human mistakes sometimes occur or tasks are carried out imperfectly.

Problem that can happen in production line is categorized into 3 (three) types;

a) Type 1 is the problem occurs since the day one of production. It is most likely related to design problem, either process design or product design.

b) Type 2 is the intermittent problem. This type of problem is caused by non robust process.

c) Type 3 is the problem that suddenly appears. This problem caused by uncontrolled change in the process.

\section{Human Factor in Production Problem}


As an element of production, human may make any error during doing their job. This error can happen because of untrained, un discipline, forgotten, lack of attention or by purposely ignoring the procedure. However, human involvement in the process is unavoidable. Several internal factor influence the human such as physiologic condition, inconsistency, physical limitation, while some external factor may also influence the human such as working environment, temperature, humidity, non ergonomic tools and equipment.

There are 4 (four) type of human errors;

1. Type 1, Failure to perform a required action

2. Type 2, Performance of an unnecessary action

3. Type 3, Performance of a required action at an incorrect time

4. Type 4, Making a substandard response

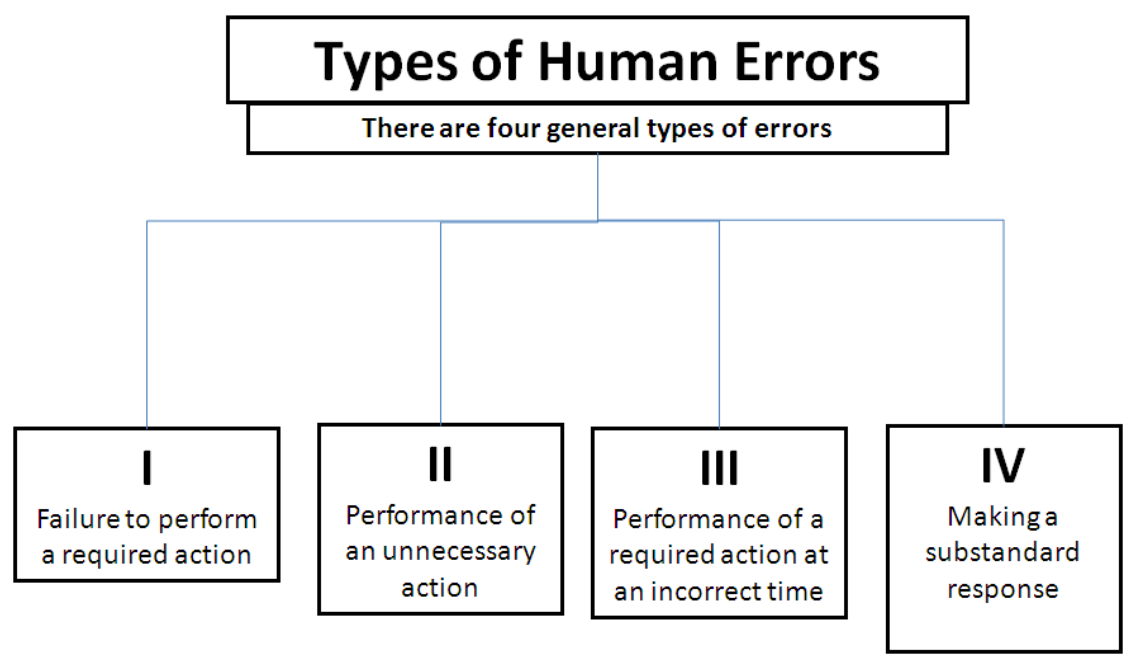

Fig.4 Types of Human Error

People are actually quite reliable. In an industrial setting one can expect that, for discrete, work related acts such as reading a five-digit number, moving control, or putting a part into place, workers will average about one error per 1000 to 10.000 acts. With highly intensive inspection, about 80 to $98 \%$ of their errors will be detected and corrected in normal reviews and inspection: more frequently, inspectors catch only 70 to $80 \%$ of the detects. A third of the undetected errors will have a significant effect. Ford motor company estimates that it experiences about 3 billion opportunities for assembly error every day. 


\section{Alert when error occurs}

There are 6 types of alert or response when error happen such as warning system (type 1). For example, when a driver does not wear seat belt, a light at dashboard will on. Type 2, gauging the characteristic. For example, by doing measurement we will know if error happen, Type 3, non responsive. For example, in an automatic car, when we want to start the engine while the gear position is not in parking mode, then the engine will not response. Type 4, self respects. In this type of alert, if the system make self correction it indicating the error occur. Type 5, talk about it, usually people will talk if error occurs. For example, if operator make a mistake when operating the machine, usually he will talk to his colleague. Type 6, teach me. When somebody came to us and asking us to teach him on how to do something, it may be indication that he made mistake.

\section{Prevention of error}

There are two type of solution to deal with errors, prevention and detection. Prevention of error is preferred in control method since it will avoid problem to occur. Errors is detected before the product or process started. The control applied prior to process such as source inspection. By implementing prevention, we can avoid mistake to happen during process or after process.

While detection is a control that applied to detect the error when the product being processed or during final inspection. In this type or detection, the defect was occur and giving the risk that defect escape to consumer. Control must be applied to all elements of production since each element potentially commits to make error.

\section{Poka Yoke method to prevent or detect error}

Coined by Japanese Engineer Shigeo Shingo in 1963, Poka-Yoke means 'mistake proofing'. The original definition was coined to define a process of avoiding incidental errors resulting from a lack of attention. Poka-Yoke can be classified as a quality assurance technique, responsible for eliminating defects in a product by preventing or correcting mistakes as early as possible. There are 6 (six) method of poka yoke for error detection such as;

- Elimination the possibility of errors thru design. 
- Replacement to more reliable process.

- Prevention of error.

- Facilitation to make work easier to perform.

- Detection of error.

- Mitigation to minimize effect of errors.

Poka-Yoke systems are traditionally classified either according to the purpose of inspection or according to the techniques employed as follow;

1. The Regulatory Function:

The regulatory function assesses the current objective then specifies the method to be used. After detecting an abnormality, the poka-yoke system may signal the occurrence or even halt processing depending on the seriousness, frequency, and/or consequences arising from the problem

\section{The Control Method :}

After an abnormality is detected, the control system stops the machine or line so that corrective action takes place immediately, thus avoiding serial-defective generation. Zero Defect Quality Control depends on the widespread utilization of this method.

\section{The Warning Method :}

When the system detects an abnormality, instead of stopping processing, it just signals the occurrence of the deviation through buzzers and/or lights so that appropriate corrective actions may be applied immediately.

\section{The Detection Function:}

The detection function, is divided into three categories in accordance with the kind of detection mechanism utilized

\section{The Contact Method:}

This method detects any deviation in shape, dimension, or any specific defect through devices which are kept in contact with the work piece at the moment of inspection. Slight color variations in the coating, for example, may be detected through this method by using special sensors capable of monitoring the light reflected from the work piece's surface.

\section{The Fixed Value Method:}


This method is used in operations where a set of moves or steps are sequentially performed. Not any one step in the sequence is missed or neglected. Usually, the method employs an automatic counter and controls the number of moves to be carried out. With these methods. Abnormalities are detected by checking for the specified number of motions in cases where operations must be repeated a predetermined number of times.

\section{The Motion-Step Method:}

When the operation is executed by standardized steps or moves, this method ensures that a worker does not mistakenly perform a step which is not part of the sequence. These are methods in which abnormalities are detected by checking for errors in standard motions in cases where operations must be carried out with predetermined motions

There are several type of poka yoke;

a) Check list or check sheet. It will help person to remind the task or step such as machine set up or job with multi tasking. Check list or check sheet shall be;

- Simple.

- Sequential.

- Has reference.

- Administrative compliance.

- Up dated.

- Readable.

- Discipline is required.

b) Labeling or color coding. It will help person in grouping or arrange the part. In some application, it will help to prevent wrong operation. Label shall be readable. If we use color coding, we shall avoid to use similar color. However, color coding is not work for color blind people.

c) Mechanical. Use the mechanical characteristic as basic of poka yoke selection such as; dimensional, shape, material properties, force and torque. Physical poka-yoke rely on some physical property of the process. This could be a physical aspect of the product, a tool or even a person.

d) Electrical. Use the electrical characteristic as basic of poka yoke selection such as current. Voltage and resistance. 
e) Sensor. Electrical sensor is widely used in manufacturing. A lot of sensor available in the market such as proximity sensor, color detection sensor, present sensor. Select the correct sensor appropriate with the need. Consider the feature of the sensor.

f) Design of product or process, in which the product and or process is designed to prevent error to happen. The use of asymmetrical geometry of product can prevent wrong orientation of product placement. The sequence step of process can prevent wrong process to happen.

\section{Discussion}

\section{Application of mechanical approach to prevent error in manufacturing process}

The use of mechanical approach to prevent error in line production now is more applicable. Principle of unsymmetrical shape being used to prevent error to occur. Dowel pin can be used to detect wrong orientation of part or machine during placement. Pin can not allow the part placed wrongly oriented.

\section{Application of mechanical approach in preventing wrong orientation and misalignment.}

1. Slot at one side of magazine to prevent wrong magazine orientation In IC manufacture, chip is attached to the metal lead frame. These metal lead frame will be put into carrier box called as magazine. The orientation of lead frame is critical to prevent error during molding. There are two possibility of error in here, first is the lead frame orientation was wrong when it is put into magazine. Second, the magazine was put wrongly oriented at molding process. Impact of this error will cause IC becoming reject product. Previously, production use human inspection to ensure no wrong magazine orientation prior to load the magazine onto mold press. However, human dependent process has high likely hood error to happen. In 2014, there were 10 cases happen that causing almost 1,200 unit IC scrapped. The idea of using the unsymmetrical shape was proposed. One side of magazine was engraved to create a slot. Then, a dowel pin was installed at magazine loader of mold press. This solution is absolutely effective to eliminate wrong magazine orientation at molding process. 


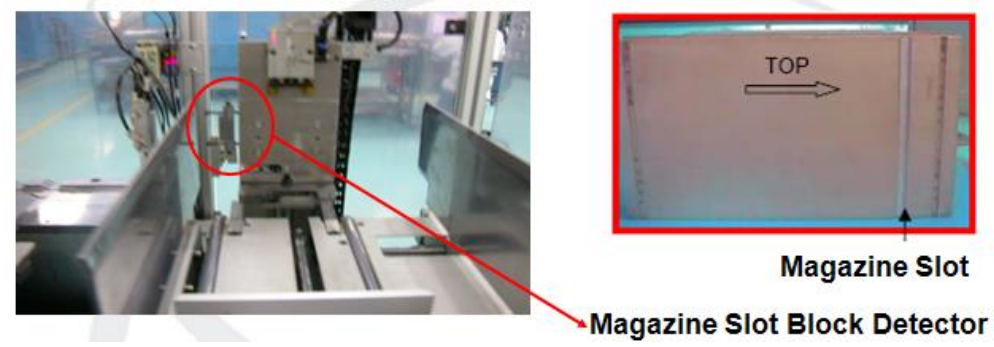

Fig.5 Slot at one magazine side to prevent wrong magazine orientation

2. Dowel Pin to prevent misaligned lead frame loading onto mold cavity

Chip encapsulation in IC assembly is to protect chip by using thermo set plastic. This process performed using mold compound. Lead frame was put onto the cavity bar, then mold cavity will be clamped and mold compound will be injected to the cavities. Misaligned position of lead frame on the cavity bar can causing mold flash and or lead frame coining. These two problems will affect the next process. Most of the time, these two defects causing the product to be scrapped. In 2014, there were more than 25 case misalignments lead frame loading that causing more than 800 defective.

A creative way to solve this issue was proposed by installed cone block or cylinder block on the cavity bar. The existence of cone block or cylinder block is functioning as detection that misaligned lead frame loading was occurring. Hence, the correction can be made immediately before processing. This error proofing is able to reduce case of misalignment lead frame loading up to $95 \%$.
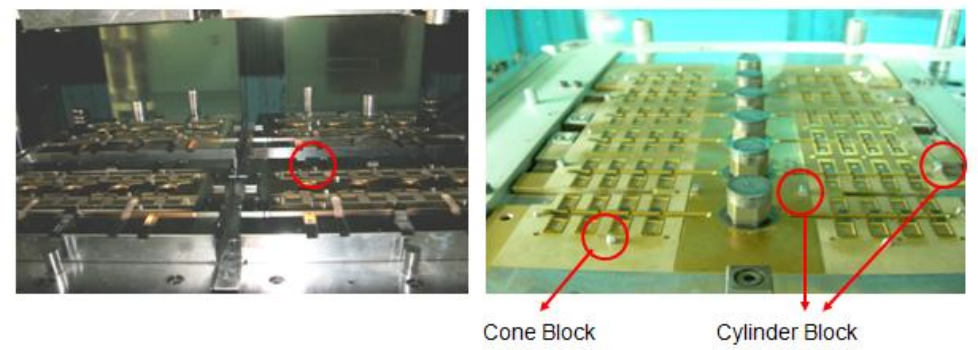

Fig.5. Cone block to detect misaligned lead frame position

\section{Summary}

1. The use of mechanical approach as error proofing is significantly improve the productivity and quality in molding process of IC manufacturer. 
2. The use of mechanical approach to eliminate or reduce error in molding process area may fan out to other areas of production.

\section{Reference}

1. Imai, Masaaki, Kaizen, The Key to Japan's Competitive Success, The Kaizen Institute, Ltd. 1996

2. Kathryn A. Ingle, Reverse Engineering, McGraw-Hill, Inc, 1994

3. Pitta, Dennis A, University of Baltimore, Baltimore Maryland USA, Product Innovation and Management in a Small Enterprice, Journal of product and brand management, Emerald Group Publishing, 2008.

4. Shingo, Shigeo, Zero Quality Control: Source Inspection and the Poka Yoke System, Productivity Press, 1986 